The Geneva Papers on Risk and Insurance, 17 (No. 62, January 1992), 143-154

\title{
Ageing and the Costs of Health Care in the Future: The Case of Holland
}

\author{
by G. W. de Wit*
}

\section{Introduction}

Both the costs and the organisation of health care are a constant reason for concern in virtually all countries. In view of the inverted operation of the law of supply and demand, it is difficult to achieve an efficient organisation and due to this the expenses can only with difficulty be confined within certain limits (e.g. as a \% of GNP).

The concern about this development as a rule does not cover more than a short period (e.g. one year or slightly longer). However, there is also a longer term development, viz. the effect of the greying of the population on the cost of health care. Because especially the elderly appeal strongly to health care, we should at an unchanged policy expect much higher health care expenses within a few decades. Possibly expenses that should be qualified as too high as a percentage of GNP.

Internationally much attention has been paid to the affordability of (social) retirement benefits during the next few decades with a view to the ageing of the population. It would be desirable to also investigate the affordability of health care.

A consideration of the development of the expenses of the Dutch health care system during the next few decades is given below, assuming an unchanged policy and taking the forecast development of the Dutch population into account.

\section{Macro expenses as policymaking instrument}

What are the expenses connected with health care? Not an easy question: what is exactly included in health care, what are the expenses connected with that definition and what are they related to?

In the past we used to give a rather restricted interpretation of health care (it existed mainly of curative care) but nowadays the interpretation is wider and we name it "care". To give an idea of the difference: in 1988 the cost of health care in the strict sense amounted to Dfl 38 billion whereas the expenses of the care sector then amounted to Dfl $45.1 \mathrm{bln}$. This difference in definition also renders international comparisons difficult.

Because the absolute amount of the care is not a very meaningful item as such, it should be related to something. It usually is to GNP. Actually not such a happy choice because GNP includes a number of elements that have little or nothing to do with the health

\footnotetext{
* Professor, Erasmus University, Rotterdam (Holland).
} 
care sector (the fact that this reference is being used internationally is not incomprehensible because it often is the only data available).

Koopmans (1989) in this connection speaks of 'an absurd behaviour' because there does not exist any causal connection between the volume of GNP and the expenses of health care. In support of his opinion he mentions that there is no reason at all to increase the costs of health care if prosperity wealth increases. I would query this statement. In spite of the fact that this statement about the application of GNP is correct, the actual cost has to be related to something.

For that reason it might be preferable to relate the cost of the care sector to disposable income, because that is where the costs have to be paid from eventually. Besides this income can be broken down e.g. by age bracket, whereas GNP is purely macro-economic data.

The following graph shows the historical development of the cost of health care both in the restricted sense and as the cost of the care sector as a \% of disposable income.

Development (health) care cost

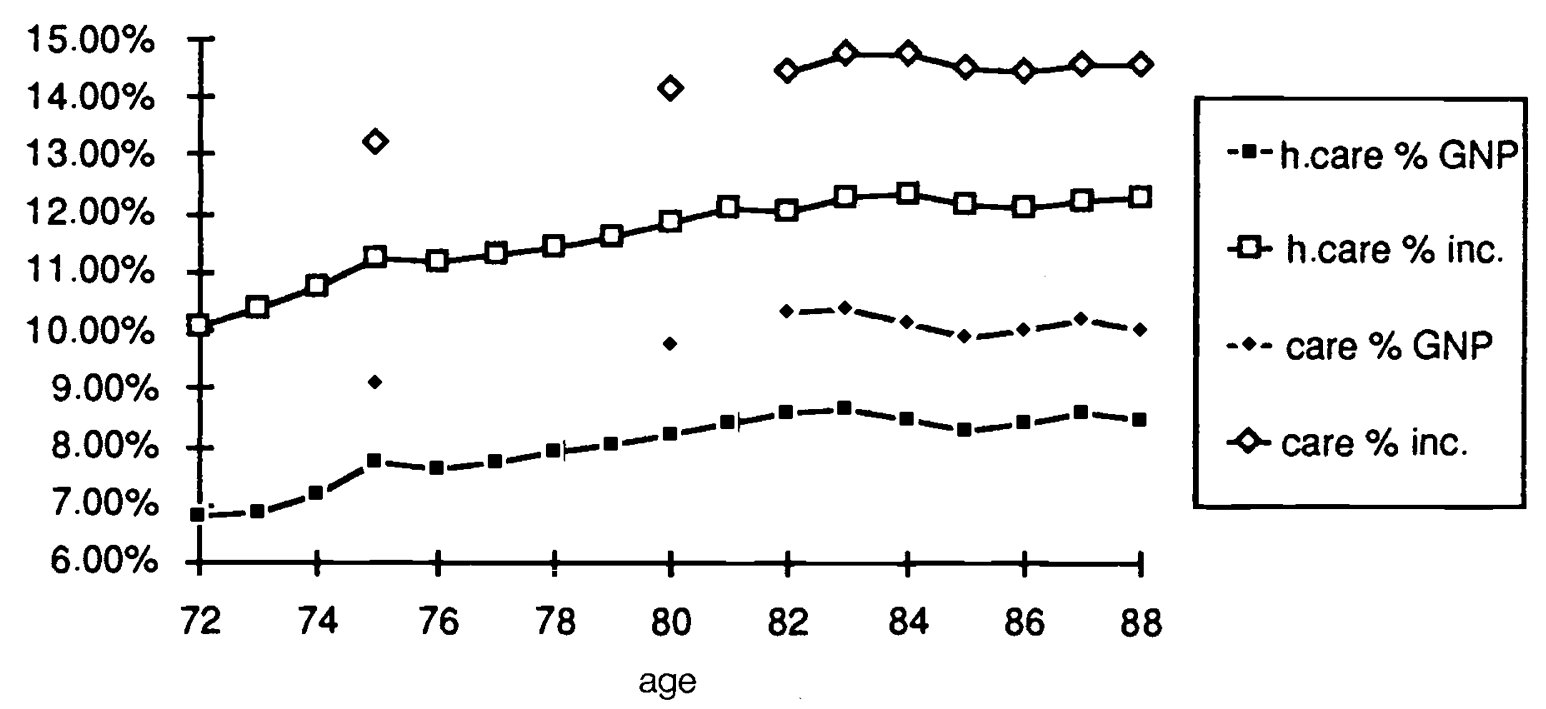

The 'income' line is somewhat more balanced than the 'GNP' line. The distance between the 'care' line and the "health care" line is a constant one.

Such a development leads to two questions:

- what is the absolute level of these lines?

- what determines the development of these lines?

We would like to comment briefly on these two questions.

No one has ever been able to decide how much we could or should spend on (health) care. When relating it to GNP it was said in the past (1974) that a maximum of $8 \%$ was reasonable. This was also asserted in international circles (McKinsey in the same period). While the costs are difficult to assess in the first place, also in connection with the definition, besides the 'value' of GNP as a yardstick is dubious as we stated before. This percentage has meanwhile become much higher in many countries and the discussion died down. 
It is not inconceivable, especially in a very wealthy country, that the inhabitants are willing/ able to spend much on their care. We use the word care intentionally because in many wealthy countries not only the immediate health care but also the care in a broader sense (e.g. for the elderly) is involved. One will require an efficient care, however. Nothing is known about both aspects, how much is one prepared to spend on it and which efficiency does exist. Those involved are hardly ever consulted when the plans are made.

We then arrive at the question: could and may an affluent country be willing to spend more on its health care that a less affluent country? We are always advocating that income should go up when wealth increases, but many are of the opinion that also allowances should share in increased affluence. Why then could not part of this increased prosperity be used for health care ? This tempted Callahan (1987) into stating: "Consumers are often prepared to spend more in certain goods, also somewhere else, than politicians think". Politicians like to use rough rules of thumb. This ' $8 \%$ ' is one of these. But is it correct to determine the costs that we are - in the opinion of the politicians that is - prepared to spend on health care by such a rough yardstick?

\section{Responsibility of the government, $\mathbf{I}$.}

Reference is often made primarily to the Constitution. For the Netherlands we find only the following in article 21, paragraph 1 :

"The Government takes measures to promote public health".

May we translate this into: the Government has to provide for:

the care being available

the care being accessible.

Not only in the Netherlands but also in much foreign literature it is stated that health care systems belong to the scarce commodities that have to be divided fairly. But are health care services scarce (with the exception of donor goods)? In my opinion they are not. The services and equipment are available but they have a price tag (if e.g. certain equipment is lacking, the reason for that is not that it cannot be supplied but - like we say-because there is no money to pay for it).

Is there then lack of money? This is often said. But is that true? We have no idea whatsoever what the cost of health care is when it is being offered and given as this should be done in the optimal and most efficient manner.

It is often said that if everything in health care would be liberalized, total expenditure would automatically become very high. Reason: it is an inverted system of supply and demand. In the current often regulated situation that might be true, but it is impossible on a freely operating market.

But if we want to make real and responsible choices we should know the expense picture of the entire efficient health care. If all of us would hold the opinion that this would be 'too expensive' we should together have to make the selection from this total picture.

In this connection there is a conflict between the public interest and that of the individual. Individually the care comes first and the cost is second. But from a public point of view the reverse is true: we first worry about the cost and only then about the care (although it is often said differently). 
For that reason the choices cannot be made by politicians only. But they will have to take the lead. But at the same time consumers have to be motivated into a different attitude towards health care.

Instead of consciously making these choices, the policy currently consists of :

- limitation of the increase (while we do not know the value of the starting point);

- ad hoc measures not to compensate for certain treatments.

Many economic measures are being taken in the Netherlands that are based on the actually found or expected increase percentages. The drawback is, however, that in this manner the perception of the absolute amount is getting lost and this amount will not be brought up for discussion either.

\section{Where are the difficulties?}

The question why the expenses develop as they do brings us to the problem of expense control. Following an initial substantial expense increase in the Netherlands (1972 -1982), the budgeting method brought about a certain stabilization (1982-1988). But the observation period is short and it is the question to what extent a strict budgeting method would permanently result in the desired expense control. Already now tension is clearly visible in medical circles (expense control in the medical sector is often a question of wage restraint rather than real medical expense control) while also the building up of waiting lists is an omen (we used to point out the long waiting lists in Britain with its budgeted National Health Service, but are there now also in the Netherlands not many before us in the queue?).

The emphasis in expense control is too heavily on the budgeting instrument. This is in fact a rather blunt instrument which hardly takes the real need or possibilities into account. It is expected from those rendering the services that they do so optimally at an inadequate price. In fact the Government passes its responsibility on to those providing the services (see also Callahan [1987] and Blank [1988]). It cannot be denied that in a number of cases budgeting leads to waste ('the budget should be used up' but than in regard of medical business, not of labour costs because that is not allowed for other reasons).

Which components of the expense increase are controllable and which are not (we only discuss the expense increase and not the level of the expenses itself, a level which - as was stated earlier - should also be included in the consideration). Grunwald (1987) made a breakdown of the expenses by exogeneous and endogeneous factors. She arrives at the following breakdown for the period $1975-1983$ :

$69 \%$ resulting from inflation

$12 \%$ resulting from more treatments (of which $11.5 \%$ due to ageing of the population)

$19 \%$ higher expenses per treatment, half of which relates to more staff, the other half to equipment).

Therefore she draws the conclusion that at least $80 \%$ is exogeneous and only $20 \%$ endogeneous. It appears from these figures that the margin for real expense control is not wide. It is to be regretted that we do not have similar breakdowns for other periods. We do know, however, the corresponding figures for the USA (OTA, 1985). For the period 1971 1981 the following percentages were found: 
$57 \%$ due to inflation;

$8 \%$ resulting from ageing of the population;

$35 \%$ due to higher treatment costs.

These figures are not essentially different, the more so if one realizes that the $35 \%$ includes the additional expense connected with liability insurance for the people providing the service.

\section{Netherlands 1975-1983}

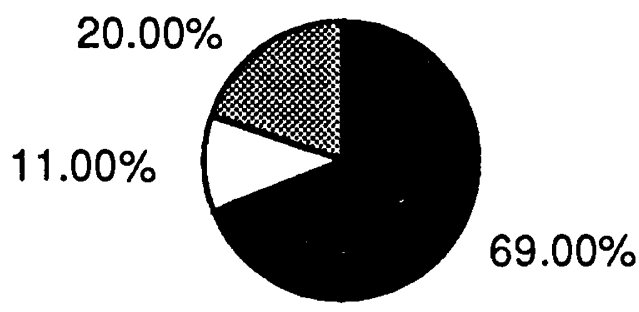

Inflation

$\square$ Ageing

Actual expense increase

\section{U.S.A. $1971-1981$}

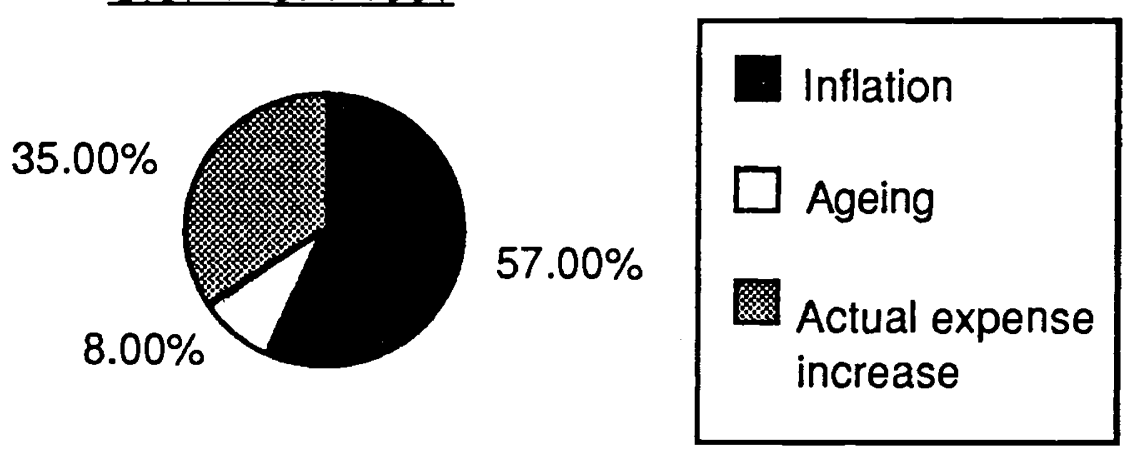

Also for the US the conclusion is that the controllable margin is small.

We usually divide health care in a number of main types: hospital, specialist, general practitioner etc.

Consequently expense control measures are directed at those sectors (in general):

for hospitals : reduction in the number of beds, budgeting

for physicians : limitation of income, promotion of the first line.

Are these now the right measures in the right place? Is the patient at the centre? No! 
All of these are macro-measures that do not take the real functions into account. Who are the consumers of the care?

If we have a look at ages we see the following:

\begin{tabular}{lccc} 
& $<20$ & $20-64$ & $>65$ \\
\hline Numbers & 26.7 & 60.8 & 12.5 \\
total expenses & 14.2 & 48.9 & 36.9 \\
hospital & 11.8 & 43.5 & 44.7 \\
specialist & 17.3 & 53.9 & 28.8
\end{tabular}

$45 \%$ of hospital expenses already now are incurred by those over 65 . Oriented expense control at the traditional breakdown would therefore:

- for hospitals boil down to the possibilities and impossibilities at nursing the elderly

- for specialists to the possibilities in the active group of the population.

The expenses for children ( $0-20$ years of age) are practically determined by the costs in the first year.

For oriented care we have to look farther into the future.

\section{Quality}

All studies on health care automatically base themselves on the assumption that care is the same and optimal in all cases. That cannot be correct. In addition to that, the market mechanism would not make sense in such an ideal situation: a care that is everywhere optimal and equal will also command the same price. At best the buyers of this care (such as e.g. insurers or employers) may negotiate a certain quantity discount.

The 400 hospitals and 10,000 general practitioners that are active in the Netherlands can impossibly always provide top quality. It is a fact of life that some are better than others. Everybody is in agreement that quality control is the duty of the Government. But the latter can of course not do much more than test against a certain average standard. Consequently one speaks in the Netherlands emphatically about quality standardizing, quality improvement and quality control. The explanation is: "at the quality standard the emphasis is on determining and defining the MINIMUM input that health care should give to achieve the desired positive effect on the health of the patient. Quality improvement includes the process that brings or keeps the care actually at a desired level. At quality control the emphasis is on measuring and assessment of the effects of health care".

The public itself, however, has an entirely different view. Assessing quality is very personal. Even if everybody assumes he or she will get an optimal treatment. Up to now all plans regarding health care, those in the past as well as those for the future reflect little of what people think about it. It is high time the consumer of health care is placed in the centre.

This could be very well done in a system with a market mechanism. He who provides a better product (service) will also ask a higher price (or in any case be in a position to do so). He who values an in his opinion better product or service could get it at an adequate price. This does not alter the fact that any provision in health care is accessible and attainable for anyone while the Government guarantees the check on the quality standard. 


\section{Opinions}

Before looking at the future we would first like to make an observation regarding opinions from other countries.

It is remarkable that virtually everywhere health care systems are considered to be a scarce commodity that should be carefully spread. This is proven nowhere. Some (Menzel [1983], Callahan [1987], Blank [1988], Majnoni [1989]) start from a diminishing marginal utility in medicine. It cannot be denied that there is a certain element of truth in this, but again: the patients hold a different opinion! The one exception is possibly the US. There do not exist worries about the total expense of health care (e.g. whether the expense as a $\%$ of GNP will go up further). Because anything is for sale. There are only three parties having worries:

- the companies which think the cost (of labour) is too high (squeezing in HMO's);

- the Government as to how the cost of medicare and medicaid can be kept under control (hence the elderly problem);

- the Government on account of the high number of uninsured persons.

The complaints (we find a good list e.g. by Field [1989]) are showing a high degree of uniformity:

- Hospitals are inefficient, they do not attain the level of industrial companies (Eichhorn [1988]);

- earnings of physicians are too high (on an average) (Kramer [1989]);

- the environment seriously affects our health ;

- our economic system leads to an unhealty industry (wrong nourishment) (Geiser [1989]).

This automatically leads to prevention. Some do not see what good this could do because also people who are leading an extremely healthy life are subject to illness (Geiser [1989]). Yet everybody is in agreement that education not to smoke (White [1988]) and consume little alcohol is extremely useful. The emphasis is mainly on the fight against smoking. It would be commendable if one would be somewhat more consciously aware of one's life-style. The Government should play a more active role in this respect (in the Netherlands this can be seen in respect of smoking) in the areas of habits (smoking, alcohol etc.) as well as nourishment and environment.

A healthier way of life would favourably affect the cost of health care. In this respect there exists a parallel with environmental problems. A better approach to the environment would result in lower expenses later on.

Health care is also a cultural phenomenon. E.g. Payer (1988) shows that there are big national differences of diagnostics and treatments. Customary practice is playing an important role. According to her there is a wide area for savings here. Maximum research is needed. Finding new pioneering developments sometimes depends on coincidence but often on systematic research as well. If antibiotics had not been discovered at the time, health care in its present form would with all kinds of infectious diseases be many times as expensive. Too little money is being spent on research. The money for research should be paid from normal health care revenues. Not from public funds where there is a continuous weighing against other interests. But not from actions on radio and television either. 
Discoveries in this environment could achieve tremendous savings in health care. Geiser (1989) asserts that e.g. transplantations are a sign of medical poverty because we do not know what caused the abnormality that necessitated the transplant.

It is obvious that ageing (which in many countries already advanced further than in the Netherlands) causes concern in many countries. Also in the Netherlands this has received too little attention. We cannot find anything about how the care of the elderly in the coming decades is being envisaged. Statements exist in other countries which do not seem to be widely accepted in the Dutch way of thinking. In this connection the following propositions could be mentioned:

- ageing and dying should become a healthy process (Geiser [1989]);

- we should get a new attitude towards ageing and death (Callahan [1987]);

- we should be contented with a certain life span (Callahan [1987]).

Especially the Americans are intensively involved in the problems of the aged. The publications by Callahan (1987) and Blank (1988) could be warmly recommended in this respect. We will revert to that later on.

\section{The responsibility of the government, II.}

A duty of the Government which has not been paid attention to so far is its duty regarding the accessibility and by this we mean affordability. It is obvious that health care is practically unaffordable for many (lower income brackets, elderly). A (high) degree of solidarity (of higher income groups and younger people) is therefore a must. Everybody is feeling the need for that and is consequently in favour of solidarity.

Yet there are limits especially because for more purposes (e.g. social security) an appeal to the same groups of persons is made.

Implementing a compulsory solidarity will always be a duty of the Government because it is difficult to achieve by competition in a free market.

The solidarity in the social sector has always been great, maybe even too much so. It is considerably smaller in the private sector. In virtually no instance the fundamental discussion about the needed degree of solidarity is further gone into, nor are there statements about the question whether this solidarity is being created among the right groups. This latter is even more important now that in the future a further appeal to the solidarity of certain groups will be made. If solidarity is not chosen in the right direction now, a future deviation will be extremely difficult. Solidarity is not constant over time.

\section{The future}

In the following we want to go into the additional expense resulting from ageing of the population. In this respect a longer period should be taken into account because measures that are connected with it cannot be realised in the short term and will besides have to be valid for a long period.

Currently $12.5 \%$ of the Dutch population is over 65 . In 2010 this figure will be $15.2 \%$, while the maximum will be reached in 2030 with $22.3 \%$. The attending expense increases will amount to $21.8 \%$ and $40.6 \%$ respectively, all these compared to 1988 .

The graph below shows the expense increases for the various years, in all cases compared to 1988 . 


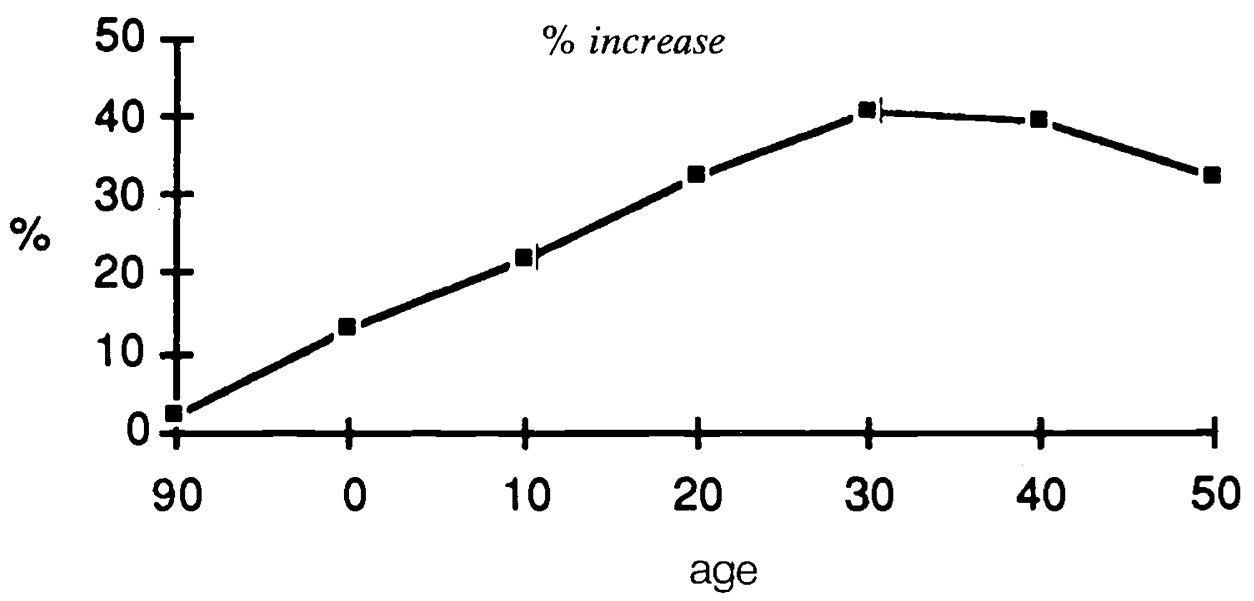

This implies that in 2030 (in terms of 1988 prices and medical possibilities) expenses will amount to Dfl 62.6 billion as against Dfl 44.5 billion now.

It is interesting to look at this expense increase for the various age brackets separately and to compare total expenses with the costs for specialists and hospitals separately. We then get the following pictures:

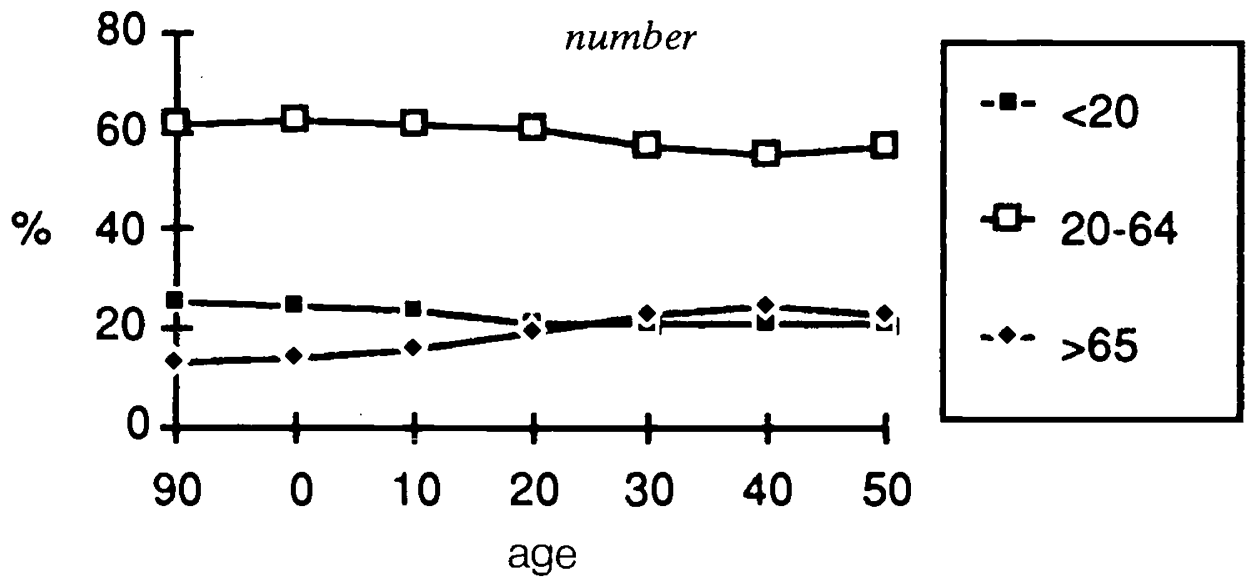

total expenses

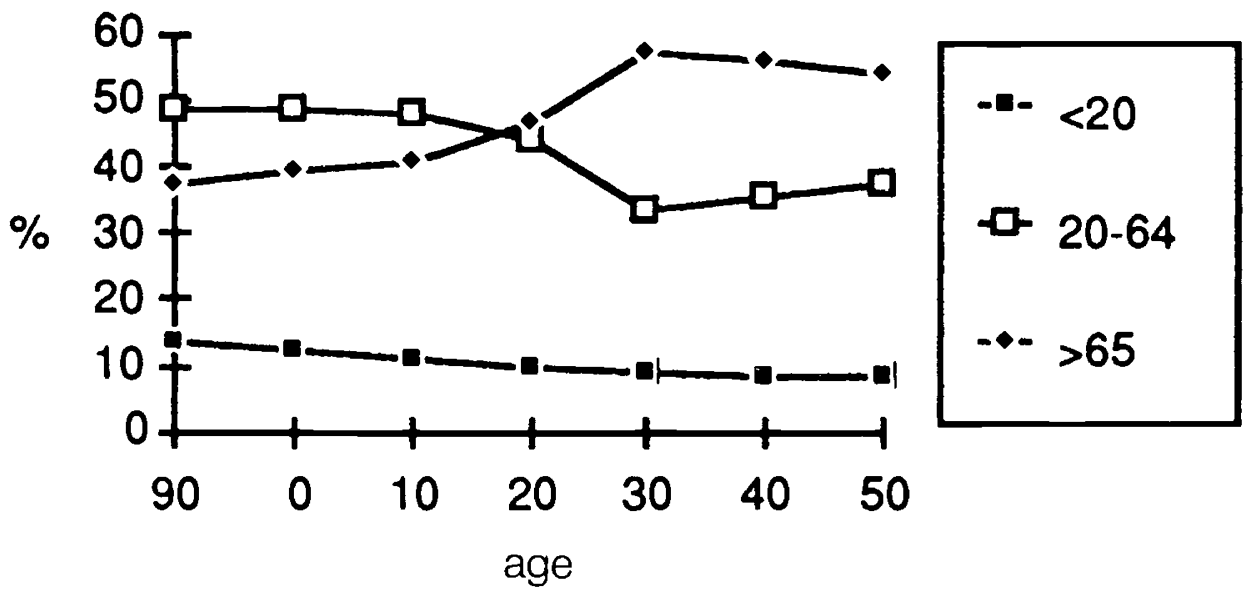



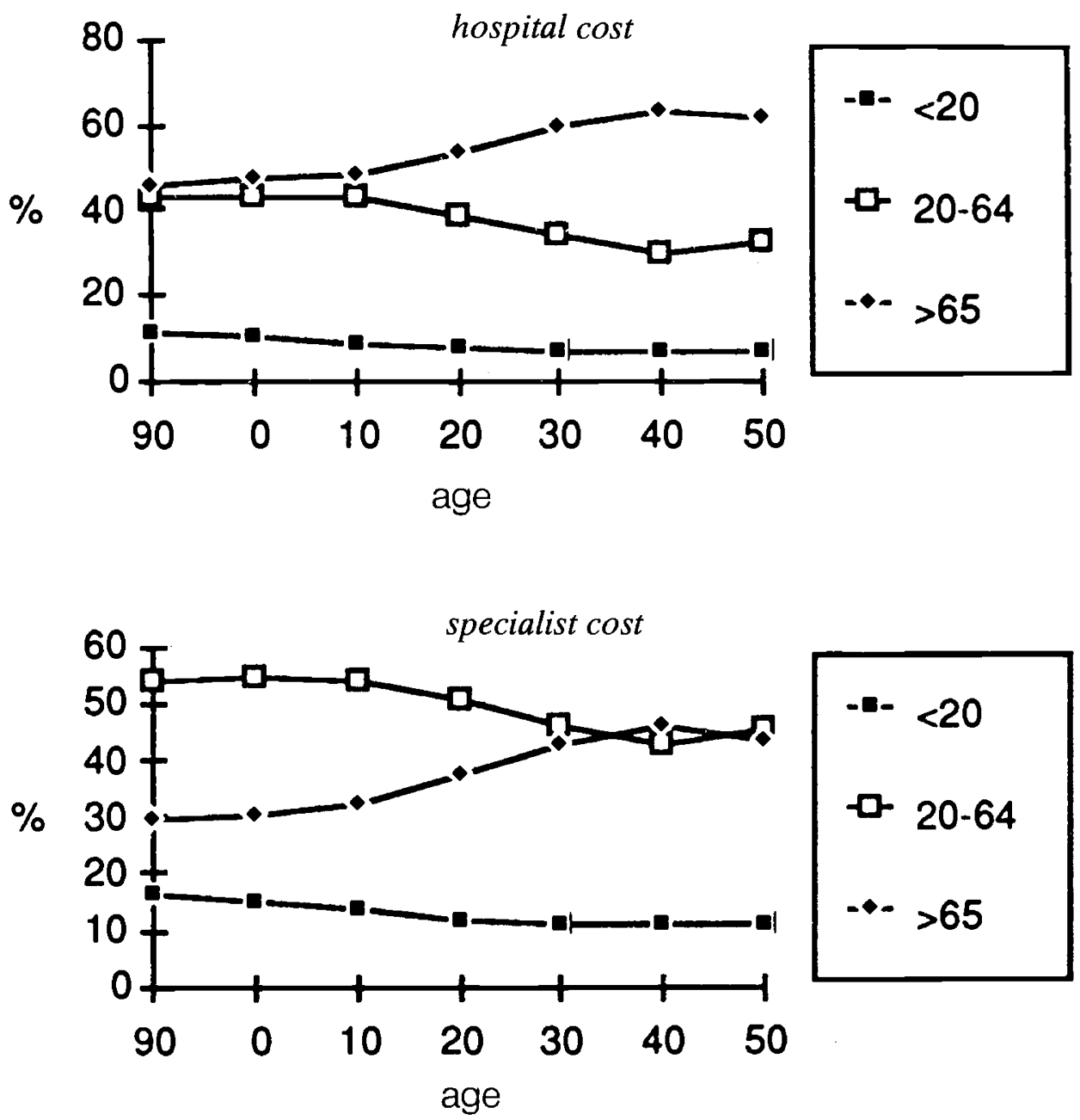

We then see the following numbers (condensed):

\begin{tabular}{|c|c|c|c|c|c|c|c|}
\hline & & & $<20$ & & $20-64$ & & 65 \\
\hline \multirow{4}{*}{\multicolumn{2}{|c|}{$\begin{array}{r}1988 \text { numbers } \\
\text { expenses } \\
\text { hospital } \\
\text { specialist }\end{array}$}} & \multirow{4}{*}{14.2} & 26.7 & & 60.8 & \multirow{4}{*}{36.9} & 12.5 \\
\hline & & & & 48.9 & & & \\
\hline & & & 11.8 & & 43.5 & & 44.7 \\
\hline & & & 17.3 & & 53.9 & & 28.8 \\
\hline \multirow[t]{4}{*}{2010} & numbers & \multirow{4}{*}{11.1} & 23.2 & & 61.6 & \multirow{4}{*}{41.0} & 15.2 \\
\hline & expenses & & & 47.9 & & & \\
\hline & hospital & & 8.9 & & 42.7 & & 48.4 \\
\hline & specialist & & 14.0 & & 54.1 & & 31.9 \\
\hline \multirow[t]{4}{*}{2030} & numbers & \multirow{4}{*}{9.2} & 20.9 & & 56.9 & \multirow{4}{*}{57.2} & 22.3 \\
\hline & expenses & & & 33.6 & & & \\
\hline & hospital & & 6.9 & & 33.7 & & 59.4 \\
\hline & specialist & & 11.2 & & 46.0 & & 42.8 \\
\hline
\end{tabular}




\begin{tabular}{|c|c|c|c|c|c|c|}
\hline & & $<20$ & & $20-64$ & & 65 \\
\hline 2050 numbers & & 20.7 & & 56.8 & & 22.5 \\
\hline expenses & 8.4 & & 37.7 & & 53.8 & \\
\hline hospital & & 6.6 & & 32.0 & & 61.4 \\
\hline specialist & & 11.2 & & 45.5 & & 43.3 \\
\hline
\end{tabular}

Care is moving up all the time: more hospital expenses (also terminal) for the elderly, more specialist treatment for the working population. Care for younger people is taking up increasingly less room. The figures for the US are somewhat lower than these. E. g. those over 65 caused $29 \%$ of the health care expenses for 1980 , a percentage that is expected to increase to 45 in 2040 . The expense increases over 1980 can be broken down by the various age brackets as follows:

\begin{tabular}{lcc} 
age & 2010 & 2030 \\
\hline$<20$ & $-4.9 \%$ & $-8.9 \%$ \\
$20-64$ & $+19.3 \%$ & $-3.4 \%$ \\
$>65$ & $+35.3 \%$ & $+118.1 \%$
\end{tabular}

Petersen and Boorsma (1987) also looked at this in the light of the additional solidarity that is now being asked from the younger ones to absorb this expense increase. Regrettably their calculations do not cover the years beyond 2000. They arrive at the following result: In 1987 those over 65 are paying only $23 \%$ of their actual expenses, the active population $(20-64)$ on the other hand $137 \%$, which means that the active ones sacrifice $4 \%$ of their incomes on behalf of those over 65 . These figures for 2000 will be : those over 65 pay $26 \%$ of their actual expenses and the actives $143 \%$. In this manner the percentage of their incomes that the active population has to spend on solidarity with the elderly will increase to $5 \%$.

\section{The elderly}

It has become clear from the foregoing that in the longer term (a few decades) especially the care for the elderly will determine the look of health care. It is remarkable that literature in Europe is paying far less attention to this than that in America.

A separate item deserves attention in this context: the terminal costs.

In 1984 in the US the cost of health care during the final year of life amounted to $1 \%$ of GNP. (Callahan, 1987). It does not seem unlikely that this figure would also be valid for the Netherlands, it might even be slightly higher in view of the high number of uninsured people in the US. At a health care percentage of $8.5 \%$ for the Netherlands this would mean that $12 \%$ of total health care expenditure is incurred for help during the final year of life. At the forecast for 2030 it is assumed that the number of deaths will increase by over $80 \%$, so that by that time $22 \%$ of the cost of health care will be spent on care during the final year of life.

The Dutch health care system will have to reflect in depth on the long term consequences of this. In primitive societies the elderly are held in high regard. In the modern 
industrial society one sometimes gets the impression that the older ones are felt as a burden. Are we, as a civilized society, willing to carry this burden, do we know a better solution (especially in a wider context) or do we simply want to set limits?

In respect of this latter some philosophies are going far. E.g. Callahan (1987) wrote a section with the title "Can there be a 'Natural Life Span' and a 'Tolerable Death"' ? He subsequently arrives at the following three recommendations:

1. Government has a duty, based on our collective social obligation to help people live out a natural life span, but not actively to help extend life medicallly beyond that point.

2. Government is obliged to develop, employ and pay for only that kind and degree of lifeextending technology necessary for medicine to achieve and serve the end of a natural life span.

3. Beyond the point of natural life span, government should provide only the means necessary for the relief of suffering, not life-extending technology.

Also Blank (1988) is going in the same direction: “... need to alter drastically public expectation and demands concerning health care". In my opinion we from our background will have great problems with such ideas.

If we have to make choices here this is not only a matter for politicians. Any changed attitude towards terminal care is everybody's business. It also touches upon the problem of euthanasia. 